Article

\title{
An Erosion-Corrosion Investigation of Coated Steel for Applications in the Oil and Gas Field, Based on Bipolar Electrochemistry
}

\author{
Claudio Mele ${ }^{1, *}$, Francesca Lionetto ${ }^{1, *}$ (i) and Benedetto Bozzini ${ }^{2}$ (]) \\ 1 Dipartimento di Ingegneria dell'Innovazione, Università del Salento, via Monteroni, 73100 Lecce, Italy \\ 2 Dipartimento di Energia, Politecnico di Milano, Via Lambruschini 4, 20156 Milano, Italy; \\ benedetto.bozzini@polimi.it \\ * Correspondence: claudio.mele@unisalento.it (C.M.); francesca.lionetto@unisalento.it (F.L.); \\ Tel.: +39-832-297-269 (C.M.)
}

Received: 10 December 2019; Accepted: 19 January 2020; Published: 21 January 2020

\begin{abstract}
In this research, a simple experimental apparatus based on a bipolar electrode (BPE) configuration was set up, in order to tackle erosion-corrosion problems of materials of interest in the oil and gas field. As a case study, the resistance to erosion and corrosion of carbon steel samples coated by Electroless Nickel Plating and by thermo-sprayed coating with the high velocity oxy fuel (HVOF) process was investigated. The main objective was to demonstrate if this simple, contactless technique could be applied to effectively discriminate the erosion-corrosion behavior of different materials in a vast range of experimental conditions. In fact, by means of polarization curves, visual inspection and morphological analysis by scanning electron microscope (SEM), the effects due to erosion-corrosion by solid particles, by fluid and those due to simple erosion were evaluated.
\end{abstract}

Keywords: bipolar electrochemistry; erosion-corrosion; oil and gas

\section{Introduction}

The oil and gas production field presents aggressive conditions in terms of erosion and corrosion. Careful attention must be given to the material selection at every stage of the design, construction and operation of piping systems and their accessories, such as bends, elbows, tees and valves [1-5]. It is therefore mandatory that the materials of such components have high erosion and corrosion resistance combined with high mechanical strength.

The erosion-corrosion process depends on the corrosive fluid, on the nature and chemical composition of metal and alloy and on the surface condition. The protective film on the metal surface could be swept away by the rapid movement of the processing fluid, possibly also containing solid particulate. Several preventive methods can be employed: appropriate design of shape or geometry to prevent turbulence, alteration of environment as settling and filtration to remove solid particles or reduction of temperature, use of highly corrosion-resistant materials, rarely cathodic protection and use of appropriate coatings [1-3,6].

The state-of-the-art of the materials used for coating components subject to erosion-corrosion involves the use of various thermal spray coating processes, including HVOF (high velocity oxy fuel), EArc (electric arc spray) and APS (atmospheric plasma spray) $[7,8]$. The coating applied by thermal-spraying processes have numerous advantages: they act as a barrier between the substrate and the aggressive marine or industrial environment, they are able to protect equipment and structures, they reduce friction between contacting surfaces, they can provide a cosmetic finishing, they can properly modify chemical, mechanical, thermal, electronic and optical properties of materials and their 
application on low-cost substrates results in increased efficiency and cost savings [7-9]. Another quite common coating technology in the oil and gas industry is related to Electroless Nickel Plating (ENP), used to improve corrosion and wear resistance of components in contact with high aggressiveness fluids. The process, based on immersion of the components into a plating bath, is an autocatalytic method in which $\mathrm{Ni}^{2+}$ ions in solution are deposited through the oxidation of a chemical compound or reducing agent, typically, sodium hypophosphite. Being an electroless process (i.e., no need for electrodes and current/potential supply), ENP allows for obtaining full coverage of hidden or low-accessibility surfaces and a very good coating uniformity. Although several studies are available in the literature on the erosion-corrosion performance of coatings, they mainly refer to specific coatings or coating-substrate systems and to particular experimental conditions [7-15].

Erosion-corrosion processes involve complex mechanical and electrochemical mechanisms whose combined action often results in a significant increase in material degradation [1,16-18]. The degradation mechanism is affected by factors controlling both corrosion and erosion. Their interaction may result in a synergistic behavior, where erosion may enhance the corrosion rate, or in an antagonistic behavior, where oxidation can slow down the erosion rate $[1,14,19,20]$. In the classical approach, the synergism is defined as the difference between the total corrosion-wear mass loss and the sum of the corrosion and wear mass losses, measured separately [18]. The interaction between erosion and corrosion has been investigated using various electrochemical and non-electrochemical methods. Non-electrochemical sensors based on the electrical resistance technique and acoustic sense technique have been developed to probe the erosion-corrosion behavior, though they have limitations in providing detailed information of the erosion and corrosion processes and their synergistic effects [21]. Electrochemical measurements, such as potentiodynamic polarization, open circuit potential measurements, ellipsometry, electrochemical impedance spectroscopy and electrochemical noise methods, give significant information about erosion-corrosion mechanisms, which greatly affect the electrochemical state of the surfaces [18]. Electrochemical techniques enable us to determine the effect of wear on the active/passive behavior of materials at different potentials and evaluate changes in the kinetics which controls the rate of corrosion [18]. Electrochemical devices based on rotating disc or cylinder electrode and slurry jet impingement facility are frequently used [7-15]. All these test methods are performed with electrochemical cell configurations based on a direct electric contact of the samples with cable connections. However, in the oil and gas industry, the electric contact is often very difficult to apply during the online inspection where it is quite hard to simultaneously control a very large array of electrodes, which sometimes are mobile in solution. To overcome the problem of electric contact, when direct wiring of the sample is not possible and a conventional electrochemical set-up cannot be used, an electrochemical and contactless technique, called bipolar electrochemistry, seems to be appealing for monitoring erosion-corrosion.

Bipolar electrochemistry is a very versatile technique, characterized by the occurrence of concomitant reduction and oxidation processes at the opposite extremities (poles) of an electrode made of electrically conductive material, called a bipolar electrode (BPE), under the application of an external electric field, without a direct ohmic contact [22-24]. In fact, when sufficient voltage is applied to the "driving electrodes", a uniform electric field is present through the electrolytic solution in which a BPE is immersed, and oxidation and reduction reactions occur at the poles of BPE [22,23]. In general, a BPE refers to any conducting object exhibiting oxidation and reduction reactions at the same time. Unlike a classic electrochemical cell with a three-electrode setup, where the driving force of the redox reactions is directly controlled by tuning the potential of the working electrode that is connected to a power supply, in the open bipolar configuration, the conductive substrate is suspended in an electrolytic solution between two feeder electrodes, without any direct physical connection between the substrate and the power supply. By carefully selecting the experimental parameters, electrochemical reactions at the surface of a conducting object can be accurately controlled [22-24]. Recent applications of bipolar electrochemistry focus on sensing, electrografting, electrodissolution, electrodeposition in fields covering chemistry, biology, materials science and device fabrication [24-28]. 
The aim of this work is to demonstrate the possibility of studying the erosion-corrosion resistance of coatings with a technique-based on the bipolar electrode configuration-that allows us to perform electrochemical measurements without the need of contacting the sample with cable connections, thus imparting notable flexibility to the choice of testing geometries, ambient and conditions. This is a quite novel application of a bipolar electrochemistry technique. In the literature, in fact, a few works report applications to corrosion screening of stainless steel in acidic solutions $[29,30]$, but to the authors knowledge, the present paper describes the first investigation in the realm of erosion-corrosion.

In this work, a bipolar electrochemistry rig has been set-up to evaluate the resistance to erosion-corrosion of three types of samples: uncoated carbon steel, chosen as the reference material and the same steel, coated with two different methods: ENP (Electroless Nickel Plating) and the thermo-sprayed HVOF process. With the designed experimental set-up, the measurements carried out in aqueous solution containing chlorides and glass microspheres allowed us to distinguish among the effects due to erosion-corrosion by solid particles, those due to erosion-corrosion by fluid and those due to simple erosion.

\section{Materials and Methods}

To perform the erosion-corrosion studies, electrochemical measurements were carried out by means of an experimental set-up based on a bipolar electrode configuration (Figure 1). The investigated specimens, with $50 \times 20 \times 10 \mathrm{~mm}$ dimensions, were made of carbon steel coated with high phosphorus Electroless Nickel, indicated as ENP, and with a thermo-sprayed coating, consisting of a nickel-base hard alloy with chromium boride dispersion, obtained with the HVOF technique, indicated as Colmonoy 6 . In Table 1 chemical composition, thickness, surface roughness and microhardness of the two coatings are reported.

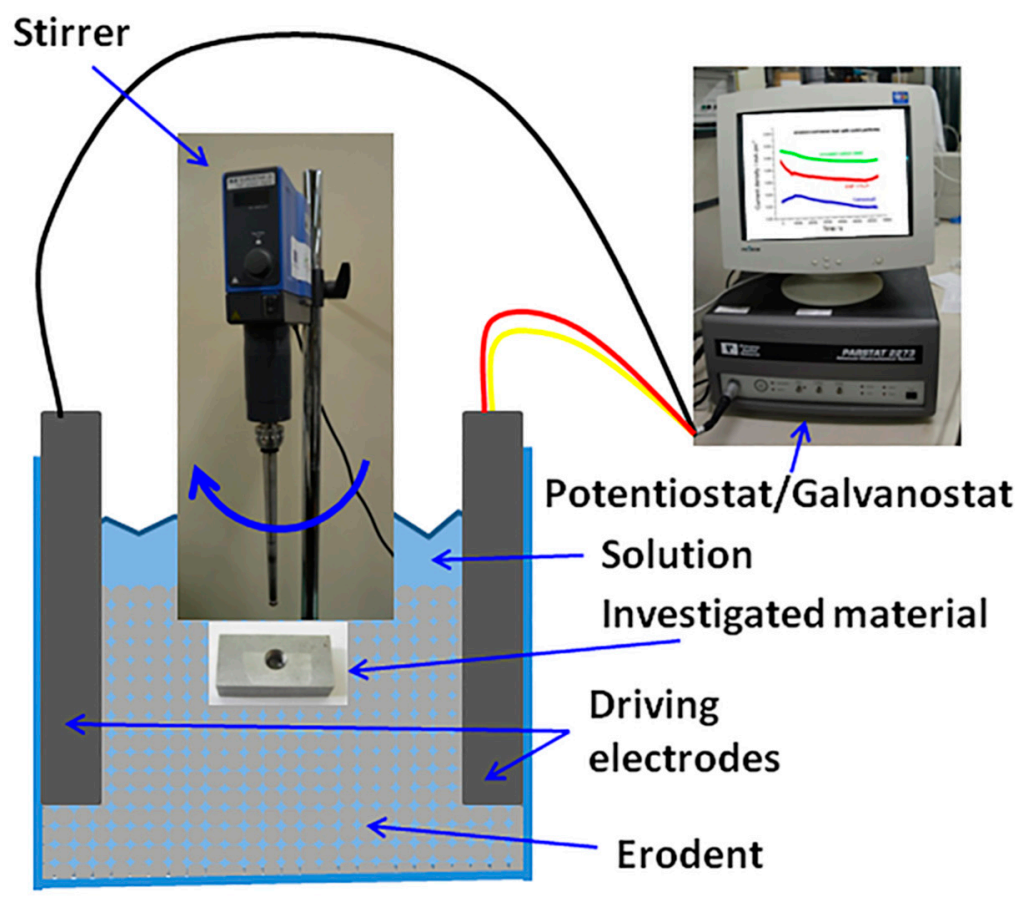

Figure 1. Layout of the experimental rig based on a bipolar electrode configuration, employed to perform erosion-corrosion measurements. 
Table 1. Properties of the investigated coatings.

\begin{tabular}{lcccc}
\hline Coating & Chemical Composition & $\begin{array}{c}\text { Thickness } \\
(\boldsymbol{\mu m})\end{array}$ & $\begin{array}{c}\text { RoughnessRa } \\
(\boldsymbol{\mu m})\end{array}$ & $\begin{array}{c}\text { Hardness } \\
\left.\mathbf{( H V}_{\mathbf{0 . 0 5}}\right)\end{array}$ \\
\hline $\begin{array}{c}\mathrm{ENP}^{1} \\
\text { Colmonoy } 6{ }^{2}\end{array}$ & ENP 11\%P & $80 \mu \mathrm{m}$ & $10 \pm 0.6$ & $631 \pm 27$ \\
\hline $\begin{array}{l}{ }^{1} \text { ENP: high phosphorus Electroless Nickel coating; }{ }^{2} \text { Colmonoy 6: thermo-sprayed coating obtained by nigh velocity } \\
\text { oxy fuel technique. }\end{array}$
\end{tabular}

The surface roughness was evaluated on 4 profiles with a length of $10 \mathrm{~mm}$ and microhardness on a Vickers scale with an applied load of $50 \mathrm{~g}$. The roughness of the ENP-coated sample was higher than Colomonoy6, whereas the hardness of on thermal sprayed coatings was more than double with respect to nickel-plated samples.

As a reference material, samples of uncoated carbon steel were also examined. These prismatic specimens were fabricated with a threaded hole on the back face (see Figure 1), through which they were screwed onto the shaft of an IKA RW20 mechanical stirrer. Two platinized titanium expanded mesh electrodes, exhibiting an area of about $10 \mathrm{~cm}^{2}$, were used as driving electrodes and fixed to the cell using a rugged Teflon holder, ensuring exact and reproducible positioning. Before measurement, each specimen was mechanically polished with emery papers of different grades down to 1200 grit, degreased with acetone and rinsed with ultrapure water. A test solution containing $600 \mathrm{ppm} \mathrm{of} \mathrm{Cl}^{-}$at room temperature and $\mathrm{pH} 6$ was employed: these relatively mild conditions were selected in order not to over-emphasize the mere corrosion contribution in the synergistic damaging process. Differential experiments were carried out without and with the addition of $300 \mathrm{~g} \mathrm{~L}^{-1}$ of glass microspheres (Graziani s.r.l.), having a size of $200 \pm 30 \mu \mathrm{m}$, representative of the erodent dimensions, hardness and mass relevant to the target application.

The experimental protocol was defined in view of ranking the three materials considered, in terms of their performance under erosion-corrosion resulting from abrasion by the slurry consisting of solid particles and a neutral, $\mathrm{Cl}^{-}$-containing aqueous electrolyte. In order to place these results in context, other types of tests were performed for selected materials: erosion-corrosion caused by the impingement of the stirred aqueous solution and mere erosion with dry particles. Erosion conditions were defined by setting a rotation speed of $800 \mathrm{rpm}$ and corrosion was controlled by applying a potential difference of 5 volts between the driving electrodes. All experiments were run for $18 \mathrm{~h}$. In the slurry tests, we employed a mixture of $150 \mathrm{~mL}$ of electrolyte and $150 \mathrm{~g}$ of particles. In the experiments with the pure electrolyte and with the dry glass microspheres, the sample was contacted with $300 \mathrm{~mL}$ of liquid and $300 \mathrm{~g}$ of particulate, respectively.

The electrochemical measurements were performed using a PARSTAT 2273 potentiostat/galvanostat (Princeton Applied Research), controlled with "Power Corr" corrosion software. Weight losses were measured by a Sartorius weight balance with an accuracy of $10^{-4} \mathrm{~g}$. The surface morphology of the samples was examined by scanning electron microscopy (SEM) with a EVO 40 instrument (Carl Zeiss AG, Jena, Germany).

\section{Results}

Two different coated systems and an uncoated reference material were chosen as the case study to prove the reliability of the proposed technique for studying erosion-corrosion problems. The morphology of the two coated systems (carbon steel coated with ENP and with Colmonoy 6) is reported in the SEM micrographs of Figure 2, where secondary electron (SE) and backscattered electrode (BSE) cross-sections are shown. 


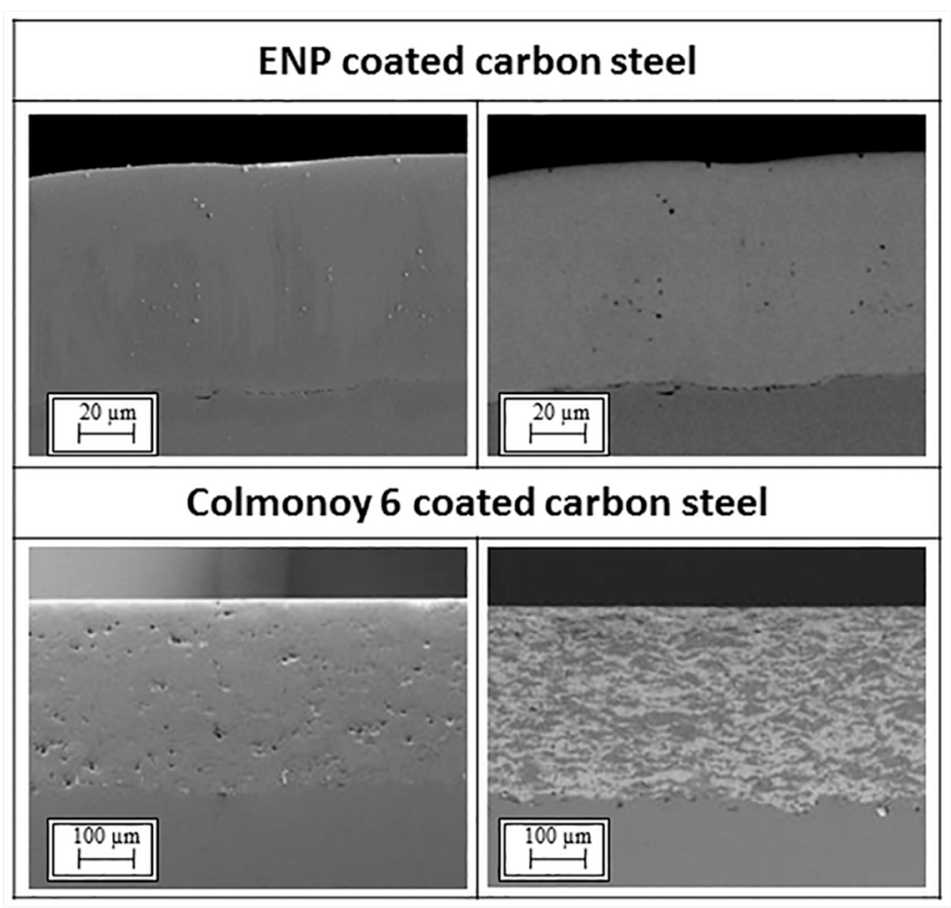

Figure 2. SE (left) and BSE (right) cross-sections of high phosphorus Electroless Nickel (ENP)-and Colmonoy 6-coated samples in pristine conditions.

ENP coating was dense and adherent to the substrate. Colmonoy 6 coating was a less dense layer, with some porosities, not interconnected, with a good adhesion to the substrate. BSE images allow us to better highlight the microstructure of Colmonoy 6, composed by a Nickel matrix with a dispersion of hard phases, mainly carbides. The signs of the final grinding process employed to get uniformity and pore closure are visible on the surface.

Figure 3 shows the chronoamperograms obtained during slurry erosion-corrosion testing for carbon steel specimens coated with ENP and Colmonoy 6 layers. It can be observed that, as expected, uncoated carbon steel was the most sensitive sample, yielding an average corrosion current density (c.d.) of $0.297 \pm 0.006 \mathrm{~mA} \mathrm{~cm}^{-2}$. The ENP coating imparts an appreciable degree of protection, resulting in a lower mean corrosion c.d. of $0.266 \pm 0.007 \mathrm{~mA} \mathrm{~cm}^{-2}$. Finally, the Colmonoy 6-coated sample was found to be notably more resistant, exhibiting a corrosion c.d. of $0.225 \pm 0.007 \mathrm{~mA} \mathrm{~cm}^{-2}$. In addition to the absolute values of the current density, reported above, that allow a global ranking of the erosion-corrosion performance of the different materials under the investigated conditions, their time trends yield some mechanistic information. Specifically, the different current density trends (increasing versus decreasing plots) observed in the initial part of the chronoamperograms can be explained by means of different model of passive film formation in analogy to what has been reported for hard metals [31]. A decreasing current trend denotes a tendency to improve passivation as erosion time lapses, this can be due to compaction of the pseudo-passivating corrosion product layer [31] or to plastic deformation of the underlying metal, resulting in lower metal activity [32]. In particular, this self-healing type of behavior can set in after an initial training period, as in the case of the Colmonoy 6 sample [33]. Finally, the increasing current density found with the ENP-coated sample after ca. $55,000 \mathrm{~s}$, might denote incipient failure of the protective layer.

The weight loss measurements performed after the erosion-corrosion testing provided limited, but significant information. Indeed, with the uncoated and with the ENP-coated sample a weight loss of approximately $10 \mathrm{mg}$ was measured. With the Colmonoy 6-coated sample, the mass loss was not appreciated. This result is consistent with what was observed by visual inspection of the samples (see below). 


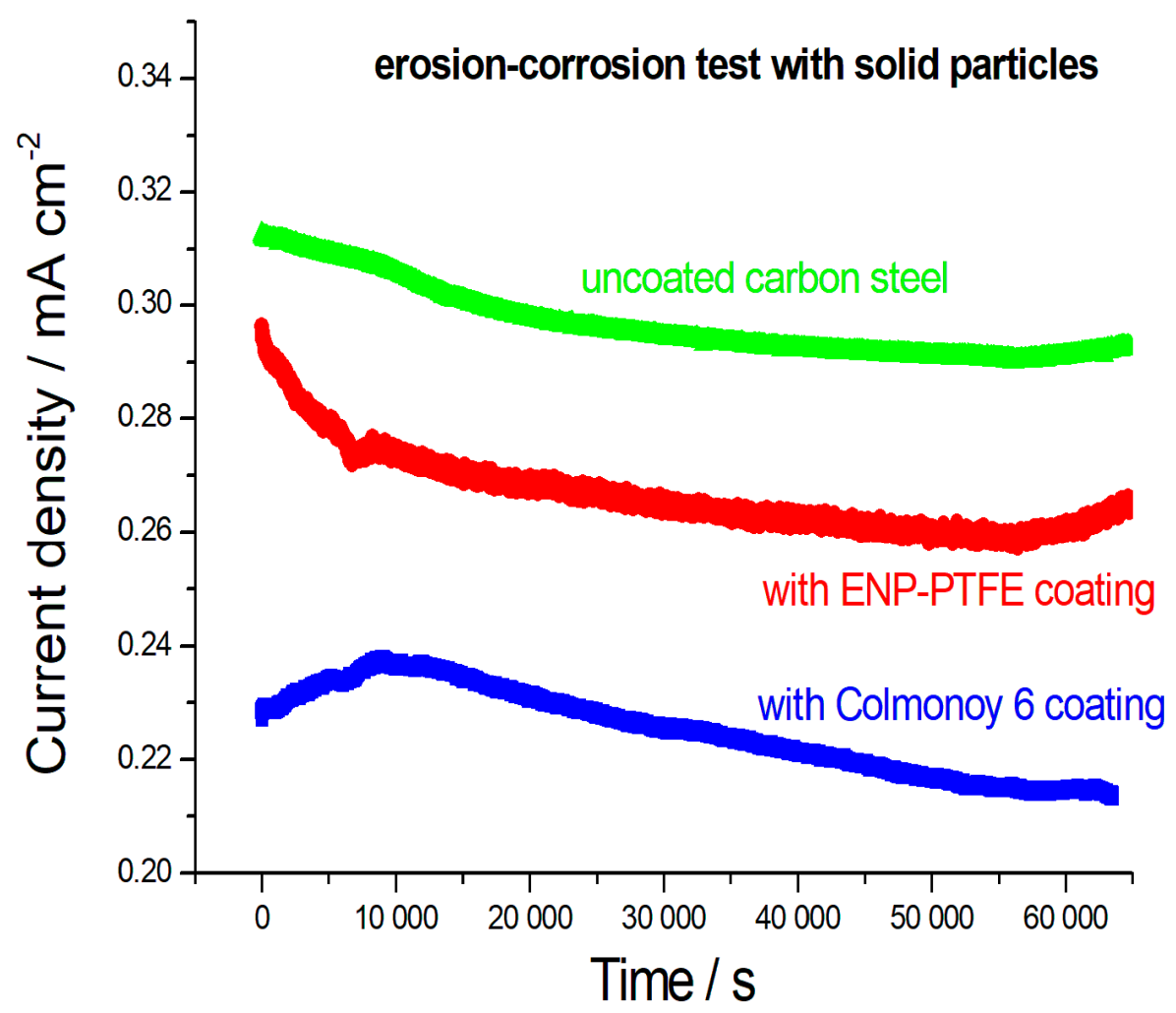

Figure 3. Chronoamperograms obtained with specimens of: uncoated carbon steel and the same carbon steel coated with ENP and Colmonoy 6, in a bipolar electrode configuration, during the erosion-corrosion test in the presence of eroding agent. A potential difference of 5 volts was applied between the driving electrodes for $18 \mathrm{~h}$, imposing a rotation speed of $800 \mathrm{rpm}$ to the specimens.

Figures 4 and 5 show macrographs and SEM micrographs of the samples tested for slurry erosion corrosion, compared with those taken with the same material in the pristine state. The images were taken on the front, back and a lateral surfaces to highlight the effects of the sample orientation with respect to the rotating shaft and the direction of rotation. In Figure 4, the uncoated specimen exhibits clear erosion marks, accompanied by the accumulation of corrosion products. The ENP-coated samples, instead, show a characteristic blackening of the surface as well as evident material removal, corresponding to the measured mass loss of ca. $10 \mathrm{mg}$. Specimens with the Colmonoy 6 coating are negligibly affected by the erosion-corrosion test, that causes only slight scratches.

The SEM micrographs of Figure 5 disclose that the uncoated carbon steel specimen undergoes both superficial and localized corrosion as a result of erosion-corrosion testing. The micrographs of ENP-coated specimens showed appreciable localized corrosion effects, together with notable material-removal marks. Colmonoy 6-coated samples show some pitting corrosion in correspondence of the erosion scratches.

The tests were completed by comparing the outcomes of erosion-corrosion testing with further damaging conditions that could highlight the peculiarities of each material. In the case of uncoated carbon steel, the least corrosion-resistant material, pure erosion conditions were also considered. Instead, in the case of the least erosion-corrosion coating, ENP, both pure corrosion and pure corrosion were considered in order to single out the individual impact of each factor. Figure 6 reports macrographs and micrographs of uncoated carbon steep subjected to pure erosion testing: evident signs left by the solid particulate are clearly observable, whereas the weight loss was negligible. 


\begin{tabular}{|c|c|c|c|c|}
\hline & & Front surface & Back surface & Lateral surface \\
\hline \multirow{2}{*}{ 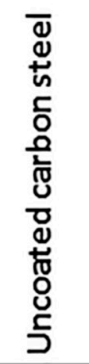 } & Pristine & & & \\
\hline & $\begin{array}{l}\text { After erosion- } \\
\text { corrosion test with } \\
\text { solid particles }\end{array}$ & & & \\
\hline \multirow{2}{*}{ 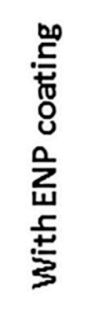 } & Pristine & & & \\
\hline & $\begin{array}{l}\text { After erosion- } \\
\text { corrosion test with } \\
\text { solid particles }\end{array}$ & & & \\
\hline \multirow{2}{*}{ 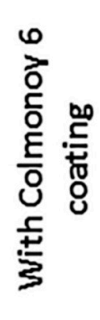 } & Pristine & & $\theta$ & \\
\hline & $\begin{array}{l}\text { After erosion- } \\
\text { corrosion test with } \\
\text { solid particles }\end{array}$ & & & \\
\hline
\end{tabular}

Figure 4. Macrographs of uncoated carbon steel samples and carbon steel coated with ENP and Colmonoy 6 , in pristine conditions and after testing for slurry erosion-corrosion under the conditions specified in Figure 2.

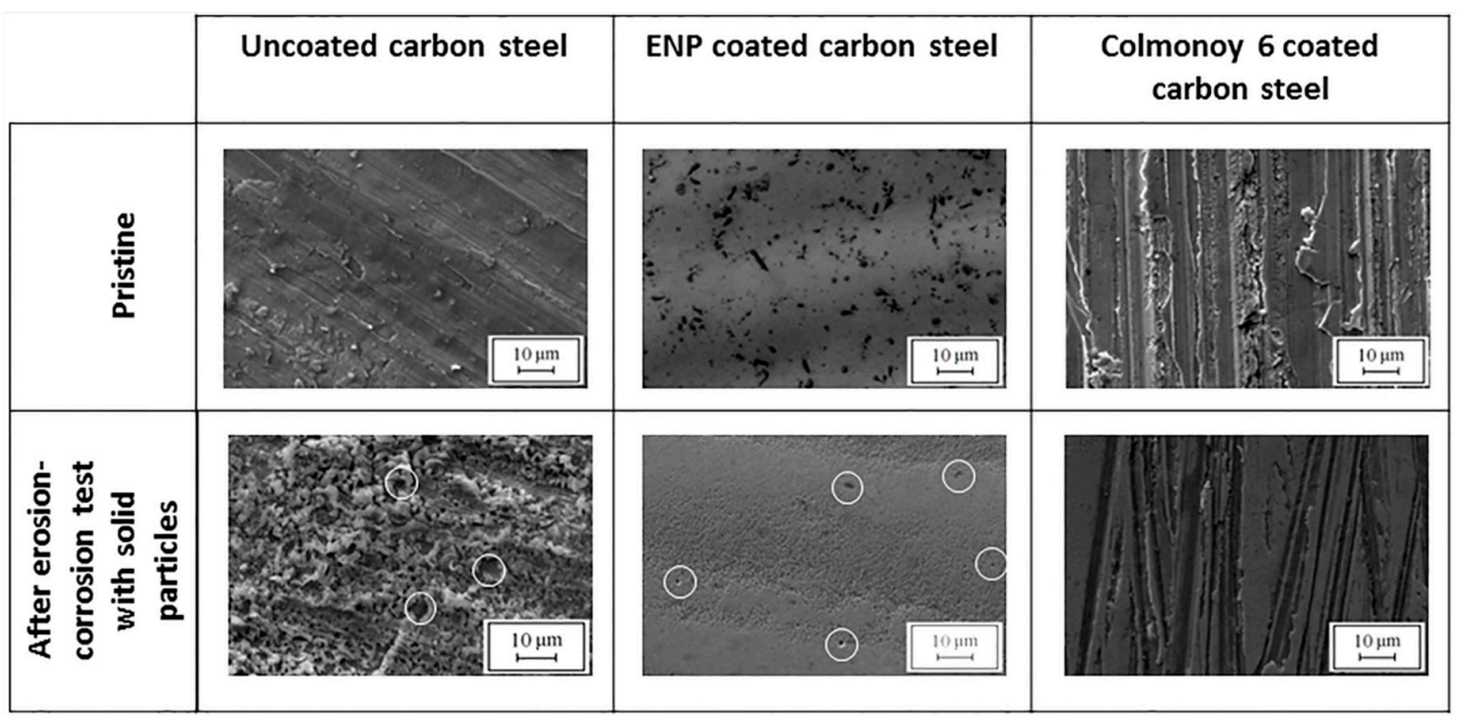

Figure 5. Scanning electron micrographs (SEM) of uncoated carbon steel samples and carbon steel coated with ENP and Colmonoy 6, in pristine conditions and after testing for slurry erosion-corrosion under the conditions specified in Figure 3. The most evident pits have been marked with white circles. 


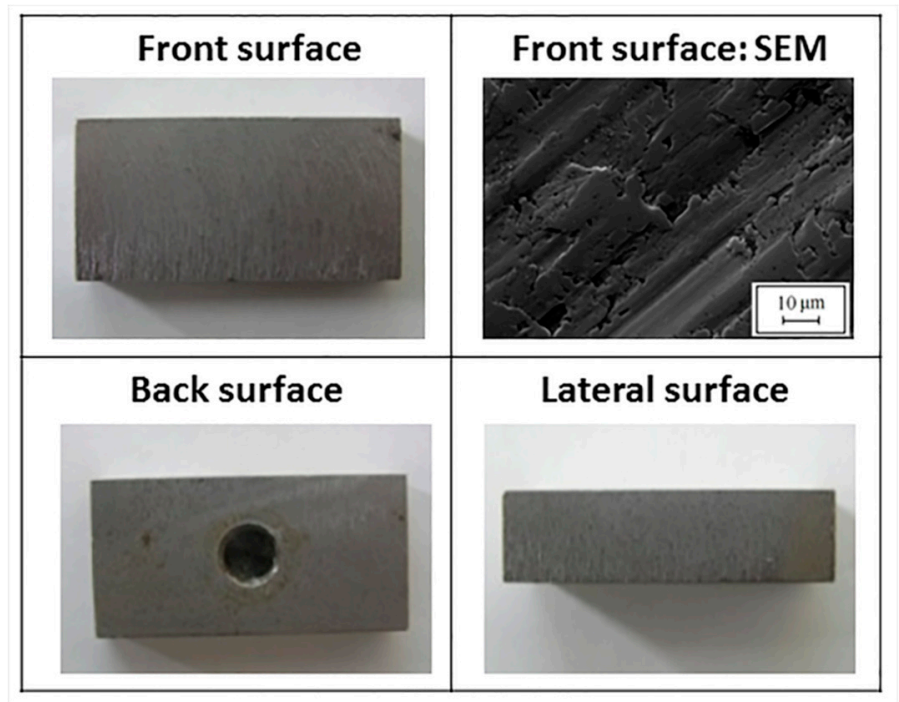

Figure 6. Macrographs and SEM micrograph of the carbon steel sample after testing for erosion with dry glass microspheres.

In Figure 7A, we show chronoamperogram of the ENP-coated sample tested under erosion-corrosion conditions caused by electrolyte impingement without particulate suspension. Comparing these results with those of Figure 3, it can be observed that the average corrosion c.d. in the slurry test was more than five times higher than that observed in the solution without eroding agent $\left(0.052 \pm 0.004 \mathrm{~mA} \mathrm{~cm}^{-2}\right)$, thus allowing us to single out the synergy of the two damaging processes. Figure 7B shows that pure erosion testing gives rise to material removal, in particular on the lateral surfaces, while the electrolyte impingement test gives rise to blackening effects on the edges, similar to those found with the slurry test. The micrographs of Figure $7 \mathrm{C}$ disclose appreciable localized corrosion effects resulting from the electrolyte-impingement test, while pure erosion gives rise to evident surface scratching. No appreciable weight loss was measured in these cases.

The above-reported erosion-corrosion tests thus allowed us to clearly determine the erosion-corrosion resistance ranking of the investigated materials. Specifically, we found that the Colmonoy 6 coating imparts the best erosion-corrosion performance under the investigated conditions while the ENP coating worsens the performance of the surface of the material, with respect to uncoated conditions, owing to enhanced localized corrosion. Indeed, on the basis of the analysis performed by evaluating the weight loss and the electrochemical and morphological differences observed between the cases of mere erosion or corrosion in the absence of sand and the case of erosion-corrosion, we noticed a high synergic effect both for uncoated carbon steel and for ENP-coated samples. In detail, in the case of the uncoated sample, the weight loss was negligible after the pure erosion test, whereas a weight loss of $10 \mathrm{mg}$ was measured as a result of the erosion-corrosion test. In the case of ENP-coated sample, the average corrosion current density in the slurry test was five times higher than that observed in the solution without an eroding agent. The Colmonoy 6-coated specimen presented negligible damages after the erosion-corrosion test. 


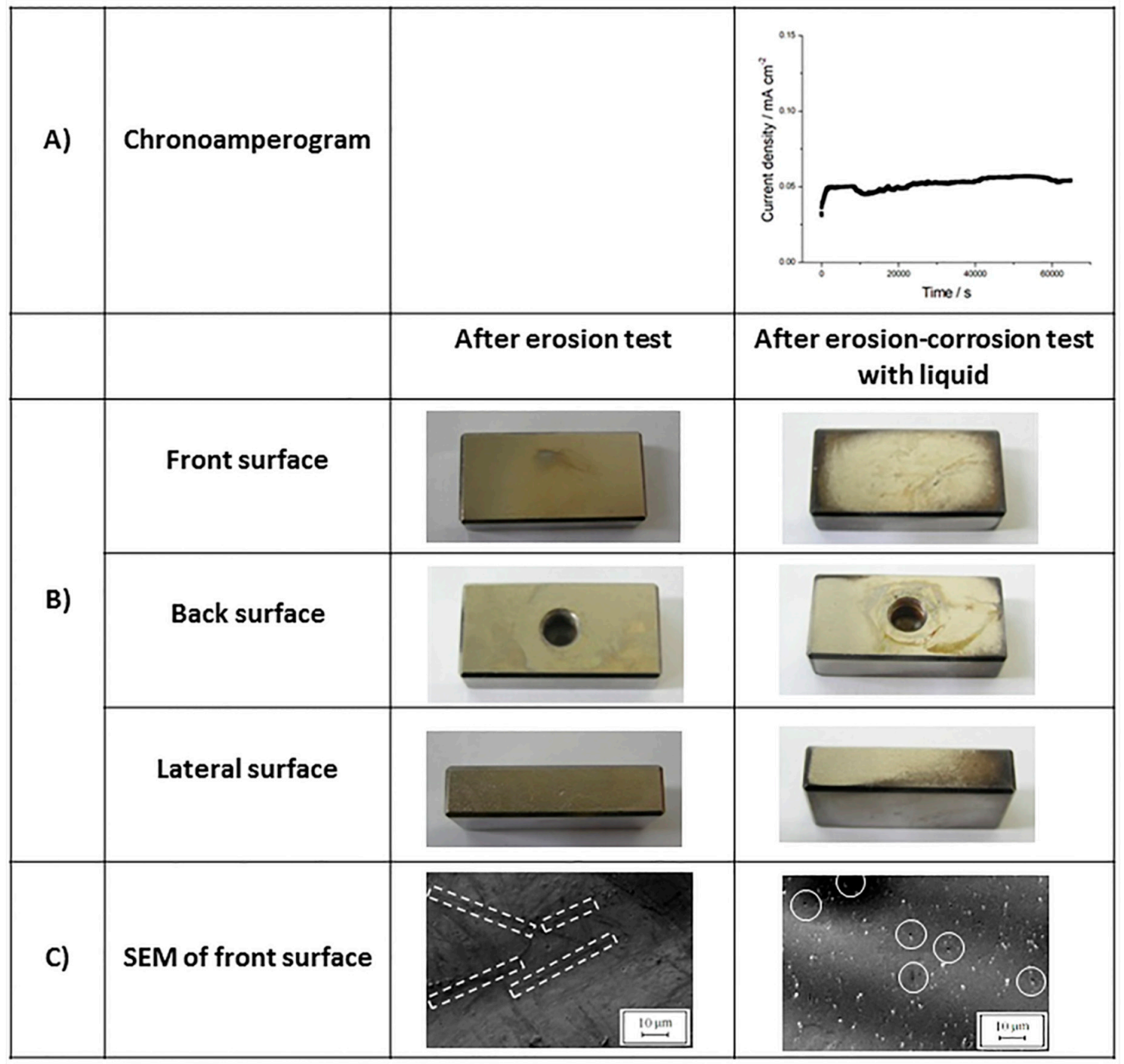

Figure 7. Erosion and erosion-corrosion test results for ENP-coated carbon steel. (A) Chronoamperograms recorded during electrolyte-impingement testing. A potential difference of 5 volts was applied between the driving electrodes for $18 \mathrm{~h}$, imposing a rotation speed of $800 \mathrm{rpm}$ to the specimens. (B) Macrographs. (C) SEM micrographs. The most evident pits have been marked with solid white circles, the most evident scratches have been marked with dashed white rectangles.

\section{Conclusions}

Bipolar electrochemistry was applied for the first time to an erosion-corrosion investigation of coated metallic samples. The effects due to the erosion-corrosion by solid particles and fluid and those due to simple erosion were evaluated and distinguished. A resistance ranking of the investigated materials was clearly determined. Their performances were correlated with the characteristics of the coatings. From slurry erosion-corrosion testing, a mass loss of $10 \mathrm{mg}$ was evaluated for the ENP-coated specimen, together with blackening of the surface, whereas it was negligible for the Colmonoy 6-coated sample. Moreover, the Colmonoy 6-coated sample was found to be more resistant than the ENP-coated one, both in terms of corrosion current density and in terms of observed surface damages. The higher erosion-corrosion resistance of Colmonoy 6 with respect to the ENP-coated sample observed in study could be related to the difference in the chemical composition and in the thickness of the coatings, combined with the lower roughness and the higher microhardness of Colmonoy 6 . 
Finally, the feasibility of this contactless approach proved the possibility to perform experiments on coated samples subject to erosion and corrosion processes, thus notably extending the scope of erosion-corrosion testing under electrochemical control.

Author Contributions: Conceptualization, C.M. and B.B.; Methodology, C.M. and B.B.; Experimental activity C.M.; Data Curation, C.M., F.L. and B.B.; Writing, Review and Editing, C.M., F.L. and B.B.; Supervision, B.B.; Funding Acquisition, C.M. and B.B. All authors have read and agree to the published version of the manuscript.

Funding: The research leading to these results has received funding from Italian National Operative Programme (PON) for Research and Competitiveness 2007-2013.

Acknowledgments: The authors would like to thank General Electric, corporate partner of the project and, in particular, Domenico Di Pietro and Paolo Guastamacchia, for providing the samples used in the tests and their surface properties.

Conflicts of Interest: The authors declare no conflict of interest. The funders had no role in the design of the study; in the collection, analyses, or interpretation of data; in the writing of the manuscript, or in the decision to publish the results.

\section{References}

1. Lu, B. Erosion-corrosion in oil and gas production. Res. Rev. Mater. Sci. Chem. 2013, 2, 19-60.

2. Okonkwo, P.C.; Mohamed, A.M.A. Erosion-corrosion in oil and gas industry: A review. Int. J. Metall. Mater. Sci. Eng. 2014, 4, 7-28.

3. Shirazi, S.A.; Mclaury, B.S.; Shadley, J.R.; Roberts, K.P.; Rybicki, E.F.; Rincon, H.E.; Hassani, S.; Al-Mutahar, F.M.; Al-Aithan, G.H. Erosion-corrosion in oil and gas pipelines. Oil Gas Pipelines 2015, 399-422. [CrossRef]

4. Smith, L. Control of corrosion in oil and gas production tubing. Br. Corros. J. 1999, 34, 247-253. [CrossRef]

5. Mele, C.; Boniardi, M.V.; Casaroli, A.; Degli Esposti, M.; Di Pietro, D.; Guastamacchia, P.; Bozzini, B. A comprehensive assessment of the performance of corrosion resistant alloys in hot acidic brines for application in oil and gas production. Corros. Eng. Sci. Technol. 2017, 52, 99-113. [CrossRef]

6. Kawahara, Y. An overview on corrosion-resistant coating technologies in biomass/waste-to-energy plants in recent decades. Coatings 2016, 6, 34. [CrossRef]

7. Reyes, M.; Neville, A. Degradation mechanisms of Co-based alloy and WC metal-matrix composites for drilling tools offshore. Wear 2003, 255, 1143-1156. [CrossRef]

8. El Rayes, M.M.; Abdo, H.S.; Khalil, K.A. Erosion-corrosion of cermet coating. Int. J. Electrochem. Sci. 2013, 8, 1117-1137.

9. Oksa, M.; Metsäjoki, J.; Kärki, J. Corrosion testing of thermal spray coatings in a biomass co-firing power plant. Coatings 2016, 6, 65. [CrossRef]

10. De Souza, V.A.; Neville, A. Corrosion and erosion damage mechanisms during erosion-corrosion of WC-Co-Cr cermet coatings. Wear 2003, 255, 146-156. [CrossRef]

11. Souza, V.A.D.; Neville, A. Corrosion and synergy in a WCCoCr HVOF thermal spray coating-Understanding their role in erosion-corrosion degradation. Wear 2005, 259, 171-180. [CrossRef]

12. Levy, A.V. The erosion-corrosion behavior of protective coatings. Surf. Coat. Technol. 1988, 36, 387-406. [CrossRef]

13. Espallargas, N.; Berget, J.; Guilemany, J.M.; Benedetti, A.V.; Suegama, P.H. Cr3C2-NiCr and WC-Ni thermal spray coatings as alternatives to hard chromium for erosion-corrosion resistance. Surf. Coat. Technol. 2008, 202, 1405-1417. [CrossRef]

14. Stack, M.M.; Jana, B.D.; Abdelrahman, S.M. Models and mechanisms of erosion-corrosion in metals. In Tribocorrosion of Passive Metals and Coatings; Elsevier, Woodhead Publishing: Cambridge, UK, 2011; pp. 153e-187e.

15. Tiwari, A.; Seman, S.; Singh, G.; Jayaganthan, R. Nanocrystalline cermet coatings for erosion-corrosion protection. Coatings 2019, 9, 400. [CrossRef]

16. Postlethwaite, J.; Nesic, S. Erosion-corrosion in single and multiphase flow. In Uhlig's Corrosion Handbook, 2nd ed.; Revie, W., Ed.; John Wiley \& Sons, Inc.: New York, NY, USA, 2000; pp. 249-272.

17. Wood, R.J.K. Erosion-corrosion interactions and their effects on marine and offshore materials. Wear 2006, 261, 1012-1023. [CrossRef] 
18. López, D.M.; Falleiros, N.A.; Tschiptschin, A.P. Use of electrochemical tests for assessment of the effect of erosive particle size on the erosion-corrosion behaviour of AISI 304L austenitic stainless steel. Mater. Res. 2016, 19, 451-458. [CrossRef]

19. Pitt, C.H.; Chang, Y.M. Jet slurry corrosive wear of high-chromium cast iron and high-carbon steel grinding ball alloys. Corrosion 1986, 42, 312-317. [CrossRef]

20. Hu, X.; Neville, A. The electrochemical response of stainless steels in liquid-solid impingement. Wear 2005, 258, 641-648. [CrossRef]

21. Xu, Y.; Luo, J.L.; Tan, M.Y. An overview of techniques for measuring the interaction between erosion and corrosion. Corros. Prev. 2017, 99, 1-13.

22. Fosdick, S.E.; Knust, K.N.; Scida, K.; Crooks, R.M. Bipolar electrochemistry. Angew. Chem. Int. Ed. 2013, 52, 10438-10456. [CrossRef]

23. Crooks, R.M. Principles of bipolar electrochemistry. Chem. ElectroChem. 2016, 3, 357-359. [CrossRef]

24. Kuhn, A.; Crooks, R.M.; Inagi, S. A compelling case for bipolar electrochemistry. Chem. ElectroChem 2016, 3, 351-352. [CrossRef]

25. Koefoed, L.; Pedersen, S.U.; Daasbjerg, K. Bipolar electrochemistry-A wireless approach for electrode reactions. Curr. Opin. Electrochem. 2017, 2, 13-17. [CrossRef]

26. Loget, G.; Zigah, D.; Bouffier, L.; Sojic, N.; Kuhn, A. Bipolar electrochemistry: From materials science to motion and beyond. Acc. Chem. Res. 2013, 46, 2513-2523. [CrossRef] [PubMed]

27. Sequeira, C.A.C.; Cardoso, D.S.P.; Gameiro, M.L.F. Bipolar electrochemistry, a focal point of future research. Chem. Eng. Commun. 2016, 203, 1001-1008. [CrossRef]

28. Phuakkong, O.; Sentic, M.; Li, H.; Warakulwit, C.; Limtrakul, J.; Sojic, N.; Kuhn, A.; Ravaine, V.; Zigah, D. Wireless synthesis and activation of electrochemiluminescent thermoresponsive janus objects using bipolar electrochemistry. Langmuir 2016, 32, 12995-13002. [CrossRef]

29. Munktell, S.; Tydén, M.; Högström, J.; Nyholm, L.; Björefors, F. Bipolar electrochemistry for high-throughput corrosion screening. Electrochem. Commun. 2013, 34, 274-277. [CrossRef]

30. Saeed, A. Application of Bipolar Electrochemistry for Corrosion Screening of Type 420 Stainless Steel in Sodium Chloride Solution. Master's Thesis, School of Materials Corrosion and Protection Centre, University of Manchester, Manchester, UK, 2017.

31. De Gaudenzi, G.P.; Bozzini, B. Meccanismi di corrosione del metallo duro. La Metall. Ital. 2017, 11-12, 39-49.

32. Bozzini, B.; Ricotti, M.E.; Boniardi, M.; Mele, C. Evaluation of erosion-corrosion in multiphase flow via CFD and experimental analysis. Wear 2003, 255, 237-245. [CrossRef]

33. De Gaudenzi, G.P.; Tedeschi, S.; Mele, C.; Bozzini, B. The effect of binder composition on the tribo-corrosion behavior of cemented carbides in simulated tertaphasic flows. In Proceedings of the Euro PM2018 Congress, Bilbao, Spain, 14-18 October 2018; Paper 3390848. 